\title{
Impact of the Palaeolithic Toolmaking on the Evolution of Cognition and Language
}

\author{
Petar Gabri, Marko Banda, Ivor Karavani \\ Department of Linguistics \\ Faculty of Humanities and Social Sciences \\ University of Zagreb \\ pgabric@ffzg.hr, mabanda@ffzg.hr,ikaravan@ffzg.hr
}

\begin{abstract}
This paper reviews in short the current research on the hypothesis of coevolution between Palaeolithic stone tool manufacture on one side, and cognition and specifically language on the other. Of particular interest are behavioral and neuroimaging studies.
\end{abstract}

Keywords: Language Evolution, Cognitive Evolution, Palaeolithic, Stone Tools, Oldowan, Acheulean, Levallois, Cultural Transmission

Received: 8 September 2018, Revised 12 November 2018, Accepted 24 November 2018

(C) 2019 DLINE. All Rights Reserved

DOI: $10.6025 / \mathrm{jcl} / 2019 / 10 / 1 / 13-18$

\section{Introduction}

In the past two decades great interest has emerged for interdisciplinary discussion on the evolution of cognition and specifically language (e.g. Jankovi and 'ojer 2015). Recent work strongly emphasizes the role of cumulative culture, i.e. products, skills and knowledge created over generations of human lifetimes, in the evolution of specific hominin cognitive abilities, including language (e.g. Lotem et al. 2017).

Moreover, it remains a controversial issue whether evolutionary changes in hominin cognition should be viewed as structural and/or functional novelties, or as exaptations of preexisting primate structures and/or functions (e.g. Stout and Chaminade 2007: 1092). Nevertheless, ample literature now acknowledges that exaptation played a major role in hominin cognitive evolution (e.g. Kolodny and Edelman 2018), but also e.g. in the evolution of hominin musculature underlying bipedalism, tool use and speech (Diogo 2018). For language specifically, it has been e.g. argued that both child first language and adult second language acquisition are served by general-purpose learning systems of declarative and procedural memory (Hamrick et al. 2018), and that linguistic semantic processing is highly dependent on modality-specific processing mechanisms of the sensorimotor system and not only on amodal or “abstract” semantic operations (e.g. Pulvermüller 2013).

Still, empirical research in the evolution of cognition and language remains relatively scarce, mostly due to serious methodological limitations (see §3). One approach has been to find behavioral correlates of specific cognitive functions in the Palaeolithic record, the archaeological period beginning with the appearance of first known hominin stone tools 3.3 mya (Harmand et al. 2015) and finishing with the end of the last glacial period (Karavani and Jankovi 2009).

1 Abbreviations: ESA=Early Stone Age ( Oldowan and Acheulean); IPS=intraparietal sulcus; SMA=supplementary motor area; $\mathrm{SMG}=$ supramarginal gyrus; $\mathrm{vPrC} \quad \mathrm{G}=$ ventral precentral gyrus; $v \mathrm{PMC}=$ ventral premotor cortex 
Research in this area has been in large part focused on inferring "modern" and "symbolic behavior" from archaeological data, such as ochre and ornament use, figurative art production, subsistence strategies etc. (e.g. d'Errico et al. 2003). The research was led by the premise that such behaviors indicate the existence of a package of "higher" cognitive abilities. However, these discussions have been heavily criticized from a methodological point of view (e.g. Botha 2009, 2012), and they currently struggle to find support in cognitive science (e.g. Garofoli 2014).

\section{Palaeolithic Stone Tools}

Recently, vast literature has appeared supporting the coevolution of cognition and language on one side, and the manufacture of Palaeolithic stone tools on the other (see e.g. Stout and Hecht 2015 for a review). Archaeology has recognized several phylogenetic phases of stone tool manufacture, and research in this topic has tried to correlate these phases with evolutionary developments in cognition, most notably visuospatial processing, executive functioning, social cognition and language.

\subsection{Lomekwian}

The earliest known hominin stone tools dated to $~ 3.3$ mya come from Lomekwi, Kenya, and consist of various rocks used for pounding, stone anvils and cores from which flakes were struck using a hammerstone (Harmand et al. 2015). The site predates the earliest known Homo specimens dated to $\sim 2.8$ mya (Villmoare et al. 2015). Cognitive implications of the Lomekwi findings, regarding among others bimanual coordination and lateralization more generally, are discussed in Lewis and Harmand (2016).

\subsection{Oldowan}

Oldowan represents the next stage of hominin stone technology, ranging from $\sim 2.6$ (Semaw 2000) to $\sim 1.42$ mya (Toth and Schick 2018: 7). It is generally considered to be characterized by flaked pebble tools, namely choppers and chopping tools, used for pounding or bone splitting. The knapping of these pebbles produced smaller flakes which could have been utilized for meat butchering (Toth 1987). Oldowan is most commonly associated with H. habilis, but it is not excluded that australopithecines engaged with Oldowan tools (Karavani and Jankovi 2009: 107). Compared to Lomekwian Oldowan is described as entailing greater abundance of flakes and smaller tool dimensions (Hovers 2015). Toth and Schick (2018) argue that Oldowan findings are suggestive of the incorporation of stone tools as a critical adaptive component which presumably led to more complex subsistence strategies, social behavior and communication.

\subsection{Acheulean}

The oldest Acheulean finds are dated to $\sim 1.7$ mya (Diez-Martín et al. 2015) and lasted in some parts of the world up to $\sim 100$ kya. Acheulean is most commonly associated with $H$. erectus and Middle Pleistocene hominins, such as $H$. heidelbergensis (Torre 2016). The most commonly recognized Acheulean tool is the handaxe and its iterations, a bifacially flaked stone tool usually of amygdaloidal form (Torre 2016). Furthermore, Acheulean assemblages also contain various flake tools. H. ergaster/erectus was the first hominin species to expand out of Africa settling vast areas of Asia and Europe. However, this expansion did not necessarily entail the spread of Acheulean, because the earliest known hominin sites in Europe exhibit a stone industry with an Oldowan tradition (Karavani and Jankovi 2009: 120). 500 kya, many European stone industries start to resemble the later Acheulean with its well-formed handaxes (Karavani and Jankovi 2009: 124). It has been argued that Acheulean tool production is more cognitively demanding relative to Oldowan due to its supposed higher hierarchical and sequential complexity (e.g. Torre 2016: 8ff.).

Due to space limitations and the fact that empirical studies almost exclusively focused on Oldowan and Acheulean, later hominin technologies will not be discussed here (but see §3). Additionally, further insights into the cognitive implications of Palaeolithic tools have come from the recent discoveries of primate tool related behaviors (see Haslam et al. 2017 for a review).

\section{Empirical Studies}

Empirical studies concerned with the coevolution of cognition and stone tool manufacture include (1) behavioral studies investigating the effects of different cultural transmission conditions on the acquisition of stone tool manufacture, and (2) neuroimaging studies of stone tool making or its observation. More detailed and critical analyses of the studies in question are, unfortunately, beyond the limitations of this paper.

Some methodological constraints include (1) difficulties in neuroimaging of stone tool manufacture, e.g. due to the static nature of the conventional methods such as fMRI, or the possibly more harmful effects of FDG-PET on subjects due to longer and more 
demanding activities (Stout and Chaminade 2007: 1096), (2) small numbers of subjects and/or shorter learning periods due to the need of collecting large amounts of raw material for tool production and the known infrastructural limitations of neuroscientific research on the number or the mere existence of subjects, and (3) recruiting modern humans to study cognitive abilities of extinct hominin species (e.g. Putt et al. 2017: 1).

\subsection{Cultural transmission studies}

To our knowledge only five such studies have been conducted while interpreting the results has been challenging. All have included subjects in the earliest learning stages. Regarding Oldowan, Morgan et al. (2015) compared transmission efficiency during flaking acquisition across five communication conditions. They found i.a. that the transmission improved with gestural and verbal teaching relative to imitation/eumlation as seen e.g. in lake quality and the number of viable flakes produced. Furthermore, they found that verbal teaching improves performance relative to gestural teaching. Morgan and colleagues argued that ESA technologies possibly generated selection for increasingly complex transmission modes. These results were in some measure replicated by Lombao et al. (2017) who compared the efficiency of imitation/emulation, and gestural and verbal teaching in the acquisition of the alternating flaking method. They reported that both teaching conditions improved performance compared to imitation/emulation and that the effects were most pronounced in the verbal teaching condition. Additionally, Cataldo et al. (2018) found in their study of flaking that subjects instructed with gesture-free verbal teaching underperform relative to subjects instructed by gestural or "full-language" teaching. Cataldo and colleagues thus conclude that while gestural communication was likely under selective pressures in the Oldowan populations, this is not necessarily the case for (spoken) language.

As to post-Oldowan techniques, Putt et al. (2014) compared the efficiency of imitation/emulation and verbal teaching in the acquisition of Acheulean handaxe manufacture. They reported no significant differences e.g. in shape and symmetry of the tools between the groups, but the non-verbal group produced more efficient flakes as seen in higher ratios of platform width to platform thickness and size to mass compared to the verbal group. Putt and colleagues concluded that (spoken) language wasn't necessary for the transmission of handaxe manufacture and that its implementation in the earliest learning stages might hinder progress. Ohnuma et al. (1997) compared the efficiency of "verbal" and "non-verbal demonstration" in the acquisition of Levallois flaking. There were no significant differences between the two conditions in the acquisition rates and mean times, and flaking success from which Ohnuma and colleagues concluded that (spoken) language was not necessary for Levallois flaking. Nonetheless, Levallois has been linked to increased demands in sequential and hierarchical planning as well as self-monitoring (e.g. Schlanger 1996: 246ff.).

It should, however, be noted that there exist considerable methodological variations in the observed studies as in the neuroimaging studies, e.g. in the selection, homogeneity and preparatory modification of raw material, learning duration and rates, presence of an experienced teacher, number of subjects etc.

\subsection{Neuroimaging Studies}

Neuroimaging studies have been mainly trying to determine the cortical structures which would have been under selective pressures, and then tying these structures to specific cognitive functions. Hecht et al. (2014) conducted a longitudinal DTI study with participants who in a two-year program acquired basic Oldowan flaking, Acheulean handaxe manufacture and Levallois flaking. They recorded fractional anisotropy changes in branches of the superior longitudinal fasciculus leading into the left SMG and vPrCG, and right pars triangularis (part of Broca's area). They thus concluded that the acquisition of Palaeolithic stone tool manufacture entails structural remodeling of inferior frontoparietal areas. Stout et al. (2008) further report from their PET study of Oldowan flaking and Acheulean handaxe manufacture by expert subjects that Oldowan and Acheulean manufacture shared increased activation compared to the control condition in specific bilateral parietal clusters in the superior parietal lobule, IPS and SMG, and additionally in BA 17 and 18 in the occipital lobe. Stout et al. (2011) conducted an fMRI study in which subjects with different degrees of experience in Palaeolithic toolmaking viewed 20-second clips of Oldowan flaking and Acheulean handaxe making. Compared to the control condition increased activation during observation of ESA toolmaking was yet again documented in the occipital and inferior parietal areas, and the precentral gyri, and was further found in the inferior temporal cortices and the right Broca's area (BA 44 and 45). These results suggest that early Palaeolithic toolmaking relieslargely on motor and visuospatial processing, but two studies have also recorded increased activity in the prefrontal cortex suggesting the involvement of hierarchical and sequential action processing.

Oldowan toolmaking has been described as involving mainly the frontoparietal sensorimotor areas, most notably the vPrCG, SMA and IPS, and the cerebellum while it is not associated with prefrontal activity (Stout 2000, 2007). Studies have concluded 
that Oldowan toolmaking relies mostly on motor and visuospatial processing with no apparent role of e.g. executive functioning, suggestive of more "ape-like" cognitive abilities (Putt et al. 2017: xxxx

with no apparent role of e.g. executive functioning, suggestive of more "ape-like" cognitive abilities (Putt et al. 2017: 4). It is here notable that the parietal cortex has witnessed a significant enlargement during hominin evolution and it is suggested that the most pronounced changes occurred around the IPS as evidenced by an inferior displacement of the lower parietal areas (Bruner 2010). Furthermore, changes in cerebellum size have been noted as well in a computational study comparing Neanderthal and modern human brains (Kochiyama et al. 2018).

Stout et al. (2008) found higher activation during Acheulean relative to Oldowan toolmaking bilaterally in the vPMC, inferior parietal areas and the right Broca's area. Furthermore, Uomini and Meyer (2013) conducted an fTCD study with expert subjects engaged in the Acheulean handaxe production and silent phonemic fluency. They noted high correlations between the hemodynamic lateralization patterns during the two tasks. It has been argued that there is a strong evolutionary connection between functional lateralization, as seen e.g. in bimanual coordination, and language (e.g. Uomini 2015). However, Putt et al. (2017) reported from their fNIRS study that subjects acquiring Acheulean handaxe manufacture in a verbal teaching condition had increased activation in the right pars triangularis compared to the non-verbal condition. These results cast potential doubt on the validity of previous results regarding Broca's area. However, comparisons between the toolmaking and control conditions were not reported. Furthermore, the study included only subjects in their early learning phases. Still and all, it has been proposed that Broca's area poses a possible connection between the evolution of toolmaking and language because of its prominent role in schematic body representation as well as sequential and hierarchical goal-directed action processing (e.g. Ruck 2014).

Additionally, Kemmerer (2012) suggested that the crosslinguistically most prevalent word orders (SOV and SVO) reflect the ways Broca's area processes actions and/or events. Moreover, Putt et al. (2017) found bilateral temporal Acheulean-related activity which they associated with auditory working memory. Finally, Putt and Wijeakumar (2018) conclude based on their earlier study that Acheulean handaxe manufacture and modern language rely on different components of working memory, with Acheulean recruiting visual and auditory working memory components not typically related with modern human linguistic processing. However, this auditory component might represent a precursor to modern verbal working memory. A further point of convergence might have been the vPMC (Putt and Wijeakumar 2018: 282).

Miura et al. (2014) conducted an fMRI study comparing observation of videos of Mousterian toolmaking and a man pronouncing Uzbek words, a language unfamiliar to the subjects. Among others, increased activation during Mousterian observation relative to the perception of Uzbek words was found in the right pars opercularis (part of Broca's area) and bilaterally in BA 6 (entailing the PMC and SMA).

\section{Conclusion}

Behavioral studies tentatively demonstrate that language was not a prerequisite for early stone tool transmission. However, they suggest that non-linguistic gestures might have been under selective pressure as early as Oldowan. Neuroimaging studies show that Acheulean compared to Oldowan activates prefrontal areas suggesting that Acheulean possibly requires significantly more executive control. While the prefrontal activity is mostly limited to BA 44 and 45 (Broca's area), the nature of the coevolution of toolmaking and language remains largely unsettled. Future research should include later hominin technologies and seek to determine the particular cognitive functions associated with Acheulean- and Mousterian-related prefrontal activity. Further accumulation of research will hopefully reveal new methodological possibilities in language evolution research.

\section{References}

[1] Botha, R. (2009). Theoretical underpinnings of inferences about language evolution: the syntax used at Blombos Cave. In: Botha, R., Knight, C. (eds.). The Cradle of Language. Oxford [etc.]: Oxford University Press, 93-111.

[2] Botha, R. (2012). Inferring modern language from ancient objects. In: Tallerman, M., Gibson, K. R. (eds.). The Oxford Handbook of Language Evolution. Oxford [etc.]: Oxford University Press, 303-12.

[3] Bruner, E. (2010). Morphological differences in the parietal lobes within the human genus. Curr Anthropol, 51, S77-88.

[4] Cataldo, D.M., Migliano, A.B., Vinicius, L. (2018). "Speech, stone tool-making and the evolution of language. PLoS ONE, 13 (1) e0191071.

16 International Journal of Computational Linguistics Research Volume 10 Number 1 March 2019 
[5] d'Errico, F., Henshilwood, C., Lawson, G., Vanhaeren, M., Tillier, A.-M., Soressi, M., Bresson, F., Maureille, B., Nowell, A., Lakarra, J., Backwell, L., Julien, M. (2003).Archaeological evidence for the emergence of language, symbolism, and music - an alternative multidisciplinary perspective. J World Prehist, 17 (1) 1-70.

[6] Diez-Martín, F., Sánchez Yustos, P., Uribelarrea, D., Baquedano, E., Mark, D. F., Mabulla, A., Fraile, C., Duque, J., Díaz, I., Pérez-Gonzáles, A., Yravedra, J., Egeland, C. P., Organista, E., Domínguez-Rodrigo, M. (2015). The origin of the Acheulean: the 1.7 Million-year-old site of FLK West, Olduvai Gorge (Tanzania). Sci Rep, 5, 17839.

[7] Diogo, R. (2018). First detailed anatomical study of bonobos reveals intra-specific variations and exposes just-so stories of human evolution, bipedalism, and tool use. Front Ecol Evol, 6, 53.

[8] Garofoli, D. (2014). Do early body ornaments prove cognitive modernity? A critical analysis from situated cognition. Phenomenol Cogn Sci, 14 (4) 803-25.

[9] Hamrick, P., Lum, J. A.G., Ullman, M. T. (2018). Child first language and adult second language are both tied to generalpurpose learning systems. Proc Natl Acad Sci U S A, 115, 1487-92.

[10] Harmand, S., Lewis, J.E., Feibel, C.S., Lepre, C.J., Prat, S., Lenoble, A., Boës, X., Quinn, R.L., Brenet, M., Arroyo, A., Taylor, N., Clément, S., Daver, G., Brugal, J.-P., Leakey, L., Mortlock, R.A., Wright, J.D., Lokorodi, S., Kirwa, C., Kent, D.V., Roche, H. (2015). 3.3-million-year-old stone toolsfrom Lomekwi 3, West Turkana, Kenya. Nature, 521, 310-5.

[11] Haslam, M., Hernandez-Aguilar, R.A., Proffitt, T., Arroyo, A., Falótico, T., Fragaszy, D., Gumert, M., Harris, J.W.K., Huffman, M.A., Kalan, A.K., Malaivijitnond, S., Matsuzawa, T., McGrew, W., Ottoni, E.B., Pascual-Garrido, A., Piel, A., Pruetz, J., Schuppli, C., Stewart, F., Tan, A., Visalberghi, E., Luncz, L.V. (2017). “Primate archaeology evolves. Nat Ecol Evol, 1, 1431-7.

[12] Hecht, E.E., Gutman, D.A., Khreisheh, N., Taylor, S.V., Kilner, J., Faisal, A.A., Bradley, B.A., Chaminade, T., Stout, D. (2014). Acquisition of Paleolithic toolmaking abilities involves structural remodeling to inferior frontoparietal regions. Brain Struct Funct, 220(4), 2315-31.

[13] Hovers, E. (2015). Archaeology: tools go back in time. Nature, 521, 294-5.

[14] Jankovi, I., 'ojer, T. (2015). “The evolution of speech and language. Opvscvla archaeologica, 37/38, 11-48.

[15] Karavani, I., Jankovi, I. (2009). Osvit ovjeanstva: po etcinašega biološkog i kulturnog razvoja. Zagreb: kolska knjiga.

[16] Kemmerer, D. (2012). The cross-linguistic prevalence of SOV and SVO word order reflects the sequential and hierarchical representation of action in Broca's area. Lang Linguist Compass, 6 (1) 50-66.

[17] Kochiyama, T., Ogihara, N., Tanabe, H.C., Kondo, O., Amano, H., Hasegawa, K., Suzuki, H., León, de M.S.P., Zollikofer, C.P.E., Bastir, M., Stringer, C., Sadato, N., Akazawa, T. (2018). Reconstructing the Neanderthal brain using computational anatomy. Sci Rep, 8, 6296.

[18] Kolodny, O., Edelman, S. (2018). The evolution of the capacity for language: the ecological context and adaptive value of a process of cognitive hijacking. Phil. Trans. R. Soc. B, 373, 20170052.

[19] Lewis, J.E., Harmand, S. (2016). An earlier origin for stone tool making: implications for cognitive evolution and the transition to Homo. Phil. Trans. R. Soc. B, 371: 20150233.

[20] Lombao, D., Guardiola, M., Mosquera, M. (2017). Teaching to make stone tools: new experimental evidence supporting a technological hypothesis for the origins of language. Sci Rep, 7, 14394.

[21] Lotem, A., Halpern, J.Y., Edelman, S., Kolodny, O. (2017). The evolution of cognitive mechanisms in response to cultural innovations. Proc Natl Acad Sci U S A, 114 (30) 7915-22.

[22] Miura, N., Nagai, K., Yamazaki, M., Yoshida, Y., Tanabe, H.C., Akazawa, T., Sadato, N. (2014). Brain activation related to the imitative learning of bodily actions observed during the construction of a Mousterian stone tool: a functional magnetic resonance imaging study. In: Akazawa, T. et al. (eds.). Dynamics of Learning in Neanderthals and Modern Humans. Volume 2: Cognitive and Physical Perspectives. Tokyo [etc.]: Springer, 221-32.

[23] Morgan, T.J.H., Uomini, N.T., Rendell, L.E., Chouinard- Thuly, L., Street, S.E., Lewis, H.M., Cross, C.P., Evans, C., Kearney, R., Torre, I. de la, Whiten, A., Laland, K.N. (2015). Experimental evidence for the co-evolution of hominin toolmaking teaching 
and language. Nat Commun, 6, 6029.

[24] Ohnuma, K., Aoki, K., Akazawa, T. (1997). Transmission of tool-making through verbal and non-verbal communication: preliminary experiments in Levallois flake production. Anthropol. Sci, 105(3) 159-68.

[25] Pulvermüller, F. (2013). How neurons make meaning: brain mechanisms for embodied and abstract-symbolic semantics. Trends Cogn Sci, 17 (9) 458-70.

[26] Putt, S.S., Wijeakumar, S. (2018). Tracing the evolutionary trajectory of verbal working memory with neuroarchaeology. Interact Stud, 19 (1-2) 272-88.

[27] Putt, S.S., Wijeakumar, S., Franciscus, R.G., Spencer, J.P. (2017). The functional brain networks that underlie Early Stone Age tool manufacture. Nat Hum Behav, 1, 0102.

[28] Putt, S.S., Woods, A.D., Franciscus, R.G. (2014). The role of verbal interaction during experimental bifacial stone tool manufacture. Lithic Technology 39 (2) 96-112.

[29] Ruck, L. (2014). Manual praxis in stone tool manufacture: implications for language evolution. Brain Lang, 139, 68-83.

[30] Schlanger, N. (1996). Understanding Levallois: lithic technology and cognitive archaeology. Cambridge Archaeological Journal, 6(2) 231-54.

[31] Semaw, S. (2000). The world's oldest stone artefacts from Gona, Ethiopia: their implications for understanding stone technology and patterns of human evolution between $2 \cdot 6-1 \cdot 5$ million years ago. $J$ Archaeol Sci, 27, 1197-214.

[32] Stout, D., Chaminade, T. (2007). The evolutionary neuroscience of tool making. Neuropsychologia, 45, 1091- 100.

[33] Stout, D., Hecht, E. (2015). Neuroarchaeology. In: Bruner, E. (ed.). Human Paleoneurology. Cham: Springer, 145-75.

[34] Stout, D., Passingham, R., Frith, C., Apel, J., Chaminade, T. (2011). Technology, expertise and social cognition in human evolution. Eur J Neurosci, 33, 1328-38.

[35] Stout, D., Toth, N., Schick, K., Chaminade, T. (2008). Neural correlates of Early Stone Age toolmaking: technology, language and cognition in human evolution. Phil. Trans. R. Soc. B, 363, 1939-49.

[36] Stout, D., Toth, N., Schick, K., Stout, J., Hutchins, G. (2000). Stone tool-making and brain activation: position emission tomography (PET) studies. J Archaeol Sci, 27, 1215-23.

[37] Torre, de la I. (2016). The origins of the Acheulean: past and present perspectives on a major transition in human evolution. Phil. Trans. R. Soc. B, 371, 20150245.

[38] Toth, N. (1987). The first technology. Scientific American, 256 (4) 104-13.

[39] Toth, N., Schick, K. (2018). An overview of the cognitive implications of the Oldowan Industrial Complex. Azania, 53 (1) 3-39.

[40] Uomini, N.T. (2015). Paleoneurology and behaviour. In: Bruner, E. (ed.). Human Paleoneurology. Cham: Springer, 121-43.

[41] Uomini, N.T., Meyer, G.F. (2013). Shared brain lateralization patterns in language and Acheulean stone tool production: a functional transcranial doppler ultrasound study. PLoS ONE, 8 (8) e72693.

[42] Villmoare, B., Kimbel, W.H., Seyoum, C., Campisano, C.J., DiMaggio, E.N., Rowan, J., Braun, D.R., Arrowsmith, J.R., Reed, K.E. (2015). Early Homo at 2.8 Ma from Ledi- Geraru, Afar, Ethiopia. Science, 347 (6228) 1352-5. 